\title{
Special Issue: Laser and optical technologies in biomedicine and ecology
}

We are pleased to present the first issue of second volume of JBPE, which focuses on laser and optical technologies for study of biological tissues and biomedical applications. This Special Issue of the Journal of Biomedical Photonics \& Engineering presents the selected papers of the Workshop "Biophotonics" of the XIII all-Russian Youth Samara conference-contest on optics and laser physics.

The XIII Youth Samara conference-contest on optics and laser physics was held in Samara Branch of P.N. Lebedev Physical Institute of Russian Academy of Sciences at November 11-14, 2015 with support of Russian Foundation for Basic Research (grant 15-32-10335), Administration of Samara Region and Samara SPIE Student Chapter. The conference program included lectures of leading scientists, reports of young $\mathrm{PhDs}$ and competition reports of students, graduate students and young researches on topical issues of coherent and quantum optics, contemporary problems of physical optics, spectroscopy and nanophotonics. The Workshop "Biophotonics" became one of the most numerous and popular seminar at the conference and included many interesting reports on applications of laser and optical techniques in biomedicine and ecology. It was held in Samara State Aerospace University (SSAU). The young scientists of SSAU Department of Laser and Biotechnical Systems annually take the most active part in the seminar. Optical methods for diagnostic of various etiology diseases as well as the optical express-techniques of implants monitoring are in the focus of their investigations. The studies were carried out with the use of backscattering spectroscopy, Raman spectroscopy, and optical coherent tomography.

Besides students and post-graduate students of SSAU, young researches from Moscow, SaintPetersburg, Saratov, Ekaterinburg, Tomsk and Irkutsk participated in the seminar Biophotonics in 2015. Their studies covered a wide range of theoretical and applied issues from the development of theoretical models of interaction of laser radiation with tissue to express-algorithm design for monitoring bioorganic liquids or optimization of the systems intended on the solution of specific medical problems. The different processes in single cells, separate organs or tissues and the whole body as well as in model biological tissue have been studied. The results of these studies were presented in 14 oral reports and 10 poster presentation.

The contest of scientific reports was held in the framework of the conference and we are pleased to announce that the report of V. Genin was recognized as the best oral report at the workshop "Biophotonics". P. Rogov and I. Novoselova took the second and the third places correspondingly. The report of N. Kozlova became the best poster report on biomedical problems. This issue of JBPE will introduce you to selected papers of the participants of the workshop "Biophotonics" of the XIII All-Russian Youth Samara conference-contest on optics and laser physics, including the papers of aforementioned participants.

The paper of P. Rogov and V. Bespalov is focused on the creation of the mathematical model of impact of intensive femtosecond laser radiation onto the human skin. Due to wide spread of femtoseconds lasers and their use in biology and medicine the study seems to be very important. The authors properly notice the lack of standards for safe levels of energy of intense femtosecond laser radiation in Russian Federation. The proposed model may be useful for determination of the maximum acceptable energy levels in new standard.

The diffusion of glycerol solutions in the rat skin ex vivo is studied in the paper of V. Genin and co-authors. The relevance and practical useful of the research is determined by the fact that aqueous solutions of glycerol are biocompatible optical clearing agents used for the light scattering reduction and the transport of radiation to deeper tissue layers. The results obtained by the authors enable to evaluate the efficiency of glycerol aqueous solutions of various concentrations as the optical clearing agents for skin parameters control.

The research of A. Vladimirov, I. Novoselova and co-authors is focused on the development of the techniques of early diagnostics and complex treatment of various diseases based on the 
methods of nondestructive control for physiological state of cells. The authors have used speckleinterferometric method allowing analyze the processes inside the cells. And the differences of processes inside and outside the cell as well as in its various parts can be found out with the use of the method.

The system of non-invasive monitoring of hemoglobin concentration with the use of pulse CO-oximetry technique is presented in the paper of I. Davydkin, N. Kozlova and co-authors. The authors' aim was to find out the optimal set of wavelengths of the probing radiation to minimize the inaccuracy for the determining the hemoglobin concentration. It was shown that while using only four semiconductor laser units (only 4 wavelengths) the obtained accuracy was comparable with accuracy which commercially available monitors achieve with 12 wavelengths. As a result such unit is acceptable for the screening-diagnostics of population in order to identify individuals with potential pathologies. Reduction of the number of probe units resulted in simplification of the scheme and its cost.

The Issue includes two papers of the researches from Irkutsk State Medical University: A. Malov and co-authors. The techniques of monitoring structural changes in bioorganic liquids under laser radiation impact are presented in the first one. The solution 'grippferon' with the base component interferon Alfa- $2 \mathrm{~b}$ as well as the gelatin solution are used as the impact objects. The authors have proposed quick software algorithms for processing speckle patterns and crystallograms, allowing the comparison of the images at different stages of the monitoring.

In their second paper A. Malov and co-authors demonstrated the results of the study of thin films of protein (albumin) under the influence of laser radiation. The so-called craquelurestructure - the structure of cracks generated on the albumin surface as the result of its drying - is formed. It was experimentally shown that the structure characteristics were changed under laser influence and depended on laser wavelength and energy density.

The study of R. Skidanov and V. Vasiliev is focused on the development of a contactless method of movement of microparticles by means of the explosion of polystyrene particles with focused laser radiation. The particles with the size more than $30 \mu \mathrm{m}$ including biological ones can be moved with the use of proposed technique. The paper is focused on the modeling of heating of polystyrene particles.

Thus, the selected papers presented in this Special Issue, introduce you to the major current issues discussed at the workshop "Biophotonics" of the XIII All-Russian Youth Samara conferencecontest on optics and laser physics.

\section{Special issue Editors:}

Aleksandra M. Mayorova, Samara Branch of P.N. Lebedev Physical Institute of Russian Academy of Sciences, Samara State Aerospace University

Valeriy P. Zakharov, Samara State Aerospace University 